\section{Successful orthotopic liver transplantation in an adult patient with sickle cell disease and review of the literature}

\author{
Morey A. Blinder, ${ }^{1,2}$ B. Geng, ${ }^{1}$ \\ Mauricio Lisker-Melman, ${ }^{1}$ \\ Jeffrey S. Crippin, ${ }^{1}$ Kevin Korenblat, ${ }^{1}$ \\ William Chapman, ${ }^{3}$ Shalini Shenoy, ${ }^{3}$ \\ Joshua J. Field ${ }^{4}$ \\ ${ }^{1}$ Department of Medicine, ${ }^{2}$ Department of \\ Pathology, ${ }^{3}$ Department of Surgery, \\ Washington University School of Medicine; \\ ${ }^{4}$ Medical College of Wisconsin, USA
}

\section{Abstract}

Sickle cell disease can lead to hepatic complications ranging from acute hepatic crises to chronic liver disease including intrahepatic cholestasis, and iron overload. Although uncommon, intrahepatic cholestasis may be severe and medical treatment of this complication is often ineffective. We report a case of a 37 year-old male patient with sickle cell anemia, who developed liver failure and underwent successful orthotopic liver transplantation. Both pre and post-operatively, he was maintained on red cell transfusions. He remains stable with improved liver function 42 months post transplant. The role for orthotopic liver transplantation is not well defined in patients with sickle cell disease, and the experience remains limited. Although considerable challenges of post-transplant graft complications remain, orthotopic liver transplantation should be considered as a treatment option for sickle cell disease patients with end-stage liver disease who have progressed despite conventional medical therapy. An extended period of red cell transfusion support may lessen the post-operative complications.

\section{Introduction}

Sickle cell disease (SCD) is an inherited disorder of hemoglobin (HbS) leading to complications in multiple organ systems. Many complications are due to either recurrent vasoocclusion or chronic hemolysis. Frequently observed manifestations of hepatic and biliary tract disease in sickle cell disease patients include vaso-occlusion of hepatic sinusoids due to the sickling process, hemosiderosis from chronic transfusions, viral hepatitis, and cholelithiasis due to chronic hemolysis. ${ }^{1}$ In many patients the cause of liver dysfunction is multi-factorial.
Acute vaso-occlusion is a common event resulting from polymerization of deoxygenated $\mathrm{HbS}$ leading to decreased pliability of red blood cell (RBC) membrane leading to sickle shaped cells, and increasing the adhesiveness of the $\mathrm{RBC}$ membrane to the endothelium of small vessels. When sickling occurs in the bone, these changes result in microvascular occlusions that cause ischemia which manifest as vaso-occlusive pain crises. In the liver, vasoocclusion of sickled RBCs occurs in the hepatic sinusoids, perhaps due to low oxygen tension. ${ }^{1}$ The obstructed hepatic sinusoids generate hepatic congestion leading to hepatomegaly and hepatocyte necrosis. In addition, Kupffer cell hypertrophy from increased phagocytosis of the sickled RBCs contributes to further sinusoidal obstruction. ${ }^{2}$ This phenomenon of sickle RBC induced sinusoidal obstruction has been termed sickle cell hepatopathy.1,3,4 Sinusoidal congestion and ischemic necrosis may lead to cirrhosis. In one study by Traina et al., among 20 SCD patients with liver dysfunction who underwent liver biopsy 19 patients demonstrated sickle cell hepatopathy from intra-sinusoidal congestion and vaso-occlusion. ${ }^{1}$

Congestion of hepatic sinusoids may manifest as a transient acute hepatic crisis associated with right upper quadrant pain, jaundice, fever, leukocytosis, increased serum aminotransferases and elevated bilirubin. ${ }^{3}$ This form of sickle cell crisis often resolves without clinical consequences. However, rarely the sequestration of sickle cells in the hepatic sinusoids may lead to more severe and potentially fatal sickle cell intrahepatic cholestasis (SCIC), which usually presents as acute hepatic failure from local ischemia. ${ }^{3,5,6}$ Untreated SCIC has been associated with a mortality rate of up to $40 \%{ }^{6}$ While treatment with red cell transfusions improves survival over supportive management alone, it is often ineffective with a mortality of $17 \%$ in chronic intrahepatic

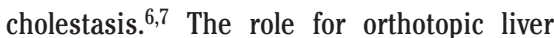
transplant (OLT) in patients with SCD and liver disease is not well defined. There have only been several cases of OLT for sickle cell disease patients with liver failure. We describe a case of a patient with sickle cell anemia and end-stage liver disease from sickle cell cholestasis who underwent a successful OLT and was maintained on perioperative transfusions with a long-term survival.

\section{Case Report}

Our patient is a 37 year old African American male with homozygous sickle cell disease whose course included intermittent vaso-occlusive crises resulting in 1-2 hospital-
Correspondence: Morey A. Blinder, Division of Hematology, Box 8125, 660 South Euclid Avenue, St. Louis, M0 63110, USA.

Tel. +1.314.3628808 - Fax: +1.314.3628813

E-mail: mblinder@dom.wustl.edu

Key words: sickle cell, liver transplantation, cholestasis, transfusions.

Conflict of interests: the authors report no conflict of interests.

Received for publication: 21 June 2012.

Accepted for publication: 10 September 2012

This work is licensed under a Creative Commons Attribution NonCommercial 3.0 License (CC BYNC 3.0).

(C) Copyright M.A. Blinder, et al., 2013

Licensee PAGEPress, Italy

Hematology Reports 2013; 5:e1

doi:10.4081/hr.2013.e1

izations per year. He has a history of cholecystectomy in 1991 and hospitalizations for acute pulmonary infiltrates in 1992 and 1998. His estimated RBC transfusion burden was $~ 20$ units prior to his OLT. Throughout his adult course aminotransferases (AST, ALT) and bilirubin were elevated (Figure 1). Viral serologies for hepatitis $\mathrm{B}$, hepatitis $\mathrm{C}$ and human immunodeficiency virus were negative and ferritin was $129 \mathrm{ng} / \mathrm{mL}$. In 2005, treatment with hydroxyurea $1 \mathrm{~g}$ daily was started and he used occasional opioids as needed.

In August 2006, 8 months prior to orthotopic liver transplant, he developed jaundice. His total bilirubin was $14.0 \mathrm{ng} / \mathrm{dL}$, alkaline phosphatase 614 , AST 176, ALT 110, and ferritin 237 $\mathrm{ng} / \mathrm{mL}$. Liver biopsy in November 2006 showed severe cholestasis, bile ductular proliferation and cirrhosis (Figure 2). RBC exchange transfusions were begun and continued every 4-6 weeks to achieve Hgb S concentrations $<30 \%$. One month prior to his transplant, he was maintained on simple RBC transfusions to maintain $\mathrm{Hgb}>7 \mathrm{~g} / \mathrm{dL}$.

In March 2007 he was admitted to the Intensive Care Unit with severe anemia, acute renal insufficiency, and deepening jaundice. Laboratory data included Hgb 5.8 g/dL, Hct 17.1, Hgb S $15.7 \%$, bilirubin 46.5 , alk phos 387 , AST 223, ALT 93, and creatinine 4.5. He was evaluated and listed for OLT with a Model for End-Stage Liver Disease score of 40. Fourteen days later he underwent an orthotopic liver transplantation from an $\mathrm{ABO}$ matched adult cadaveric donor.

The transplantation was accomplished with minimal blood loss. During surgery the patient was transfused with 3 units of packed RBCs, $1000 \mathrm{~mL}$ of $5 \%$ albumin and 3 liters of crystalloid. The donor graft appeared normal; 


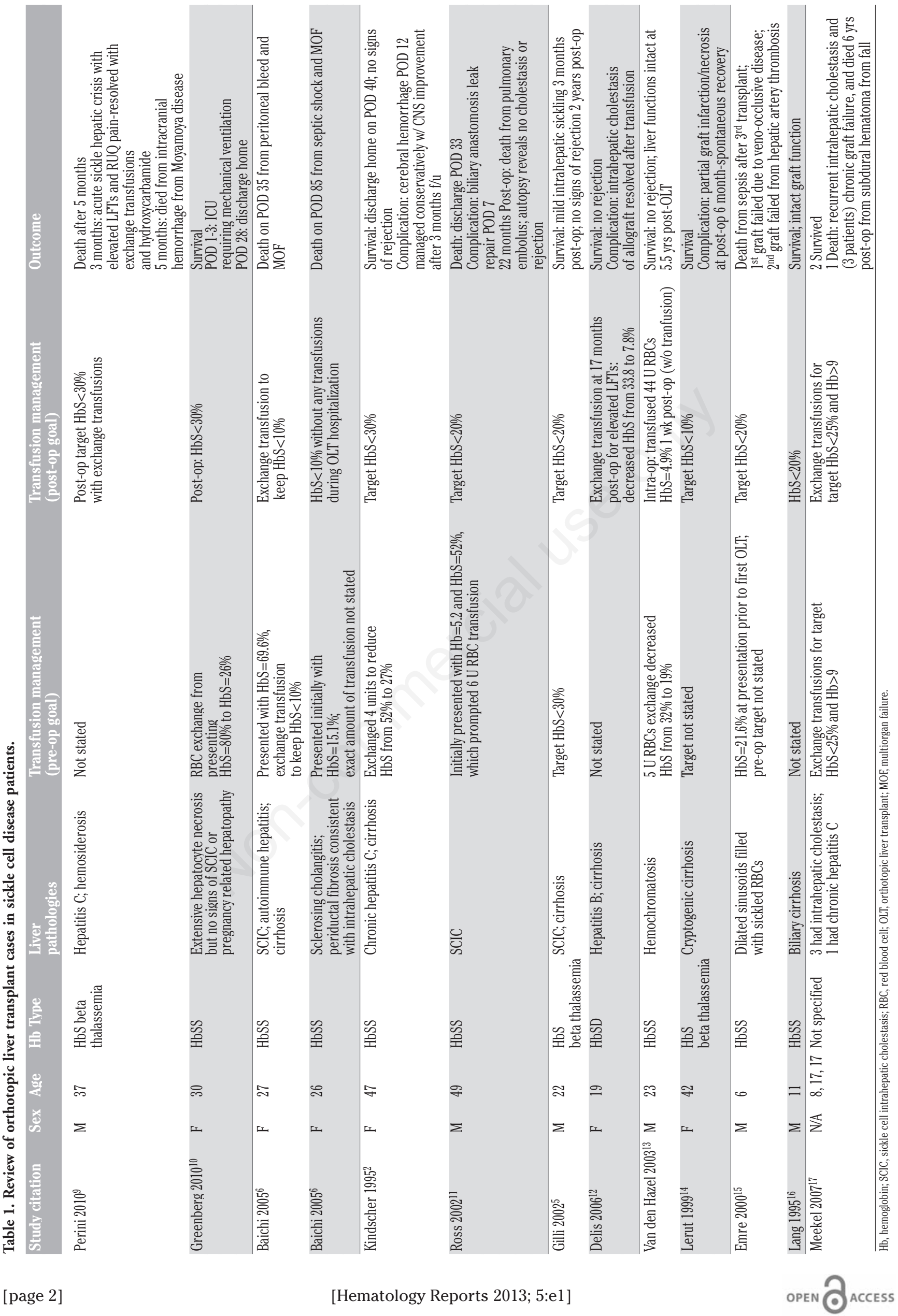


the cold ischemia time was 9 hours and the warm ischemia time was 28 minutes. The graft liver was placed in a standard piggyback fashion with bile duct-to-duct anastomosis. The liver explant showed cirrhosis with marked autolysis, and cholestasis with bile duct proliferation.
The post-operative course was complicated by seizures and acute respiratory distress, which required intubation during the postoperative course. His Hgb was maintained throughout the hospital course between 7-10 and Hgb $\mathrm{S}<2 \%$ with RBC transfusions. His urine output, lung function and mental status

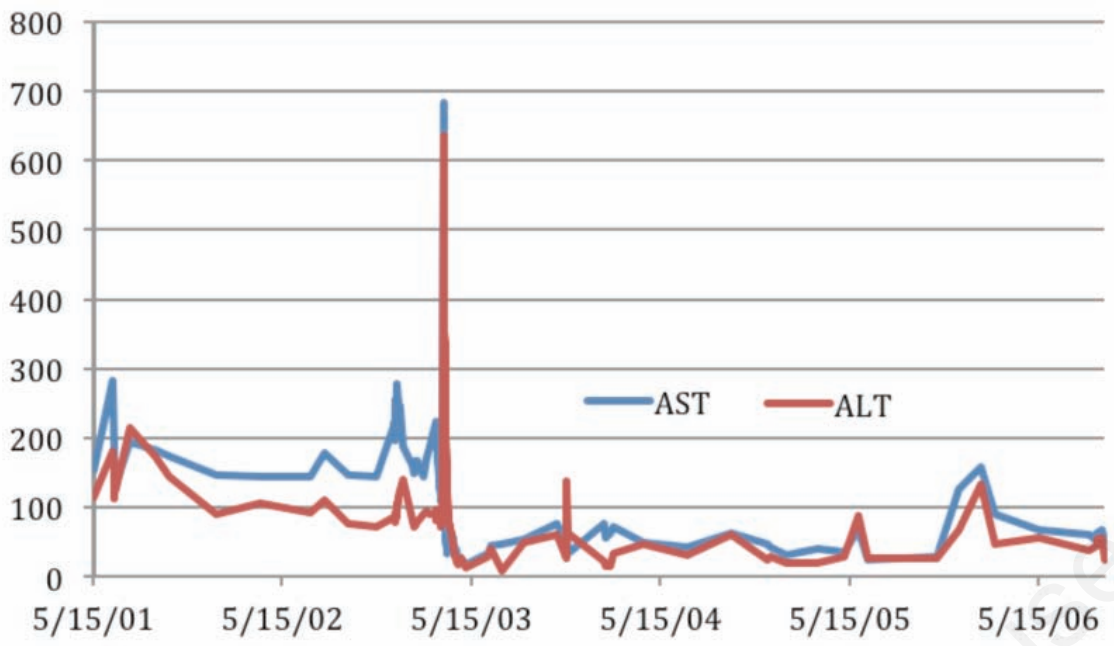

Bilirubin (mg/dL)

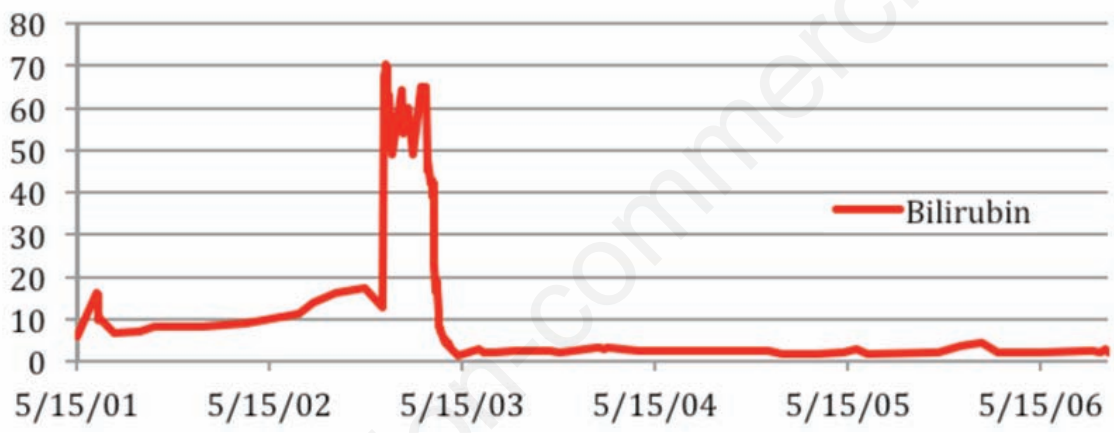

Figure 1. Aspartate aminotransferase/alanine aminotransferase (AST/ALT) (IU/L), and bilirubin (mg/dL).

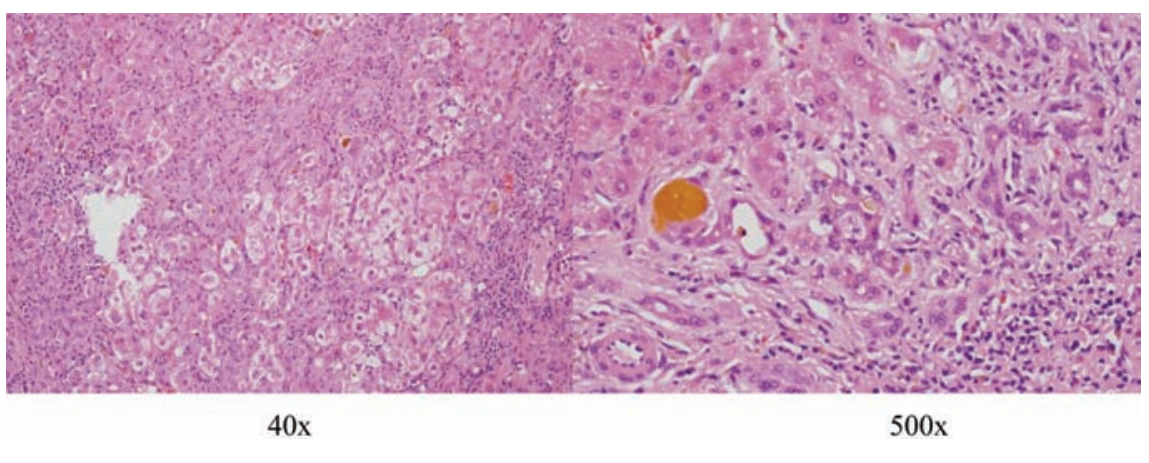

Figure 2. Liver biopsy in 2006 - severe cholestasis with fibrosis, ductular proliferation and cirrhosis (Haematoxilyn and Eosin stain).

improved gradually, and he was discharged on the postoperative day 31 in stable condition.

The patient received immunosuppression with mycophenolate mofetil, prednisone, and tacrolimus. The prednisone was gradually tapered and he was maintained on mycophenolate mofetil and tacrolimus long-term. He was maintained on 2 units RBC transfusions every 4 weeks for target of $\mathrm{Hgb}$ of $10 \mathrm{~g} / \mathrm{dL}$ for one year. His AST and ALT have decreased since the transplantation and liver function has improved (Figures 1 and 2). He had no post-operative sickle cell related complications and 12 months after transplant RBC treatments were stopped and he has been maintained on hydroxyurea.

\section{Discussion and Conclusions}

SCIC is a highly fatal complication of sickle cell disease. It has been documented that intrahepatic cholestasis has a mortality of $40 \%$ without the use of exchange transfusions. ${ }^{6,8}$ In a review of 26 reported patients, Khurshid et $a l$. found that with exchange transfusion therapy, the mortality from intrahepatic cholestasis was $17 \%$ suggesting that it remains a potentially fatal condition despite medical treatment. $^{7}$ In the patient reported here, RBC exchange transfusion therapy every 4-6 weeks for 3 months prior to liver transplantation was successful to maintain a target $\mathrm{Hgb} \mathrm{S}<30 \%$, but his liver function continued to decline. In these patients, OLT becomes the only therapeutic option.

There have been few reported cases of OLT in patients with sickle cell disease. A review of the literature identified 10 adult and 5 children with sickle cell disease (Table 1).,5,6,9-17 In 6 of the 10 reported adult cases, liver transplantation resulted in improved function and longterm survival. Of the 4 that resulted in postOLT death, 2 were from causes unrelated to the OLT or liver dysfunction (1 from intracranial bleed 5 months post-op due to pre-existing vascular anomaly and 1 from pulmonary embolism 22 months post-op). Nevertheless, sickle cell related allograft complications occurred in 5 of the 6 survived cases. Among 3 of 5 pediatric cases, transplantation was successful.

There are a number of challenges in considering OLT for sickle cell disease patients. First, surgery itself presents as a procedure with high morbidity and mortality risk. Early studies show on average $10 \%$ mortality and $>50 \%$ risk of perioperative complications in sickle cell disease patients undergoing a variety of surgical procedures but this can be reduced substantially with preoperative RBC transfusion. ${ }^{17,18}$ Sickle cell related complications such as intrahepatic sickling and vaso-occlusion can recur in the graft causing deterioration in 
function. ${ }^{5,12,14,15,17}$ Preoperative transfusion therapy can be used to mitigate the post-op complications. The National Preoperative Transfusion Study evaluating the risk of cholecystectomy in SCD patients found that post-op complications of SCD were higher in the nontransfused than the transfused group. ${ }^{19}$ Our patient was heavily transfused in preparation for his liver transplant to decrease sickle cell related complications. Notably, post-operative transfusion therapy has been utilized by a majority of the OLT cases to reduce risk of long-term graft sickle cell related complications. Nevertheless, the intensity and duration of transfusion therapy is not well defined and varies between studies. The experience with our patient suggests that aggressive RBC transfusion is warranted; however, chronic transfusion therapy places patients at risk for transfusion related iron overload.

Liver failure secondary to sickle cell intraheptic cholestasis is a complicated clinical problem and in our case, medical management with hydroxyurea, and aggressive RBC transfusions were not able to reverse his declining liver function. The current experience and role for OLT in sickle cell disease patients is limited. This case had a successful outcome with OLT plus RBC support. OLT should be considered as treatment option for sickle cell disease patients with advanced liver failure.

\section{References}

1. Traina F, Jorge SG, Yamanaka A, et al. Chronic liver abnormalities in sickle cell disease: a clinicopathological study in 70 living patients. Acta Haematol 2007;118: 129-35.

2. Kindscher JD, Laurin J, Delcore R, Forster J. Liver transplantation in a patient with sickle cell anemia. Transplantation 1995; 60:762-4.

3. Banerjee S, Owen C, Chopra S. Sickle cell hepatopathy. Heptology 2001;33:1021-8.

4. Shao S, Orringer E. Sickle cell intrahepatic cholestasis: approach to a difficult problem. Gastroenterology 1995;90:2048.

5. Gilli SCO, Boin IFS, Leonardi LS, et al. Liver transplantation in a patient with S/beta-thalassemia. Transplantation 2002; 74:896-8.

6. Baichi, MM, Arifuddin RM, Mantry PS, et al. Liver transplanatation in sickle cell anemia: a case of acute sickle cell intrahepatic cholestasis and a case of sclerosing cholangitis. Transplantation 2005; 80:1630-2.

7. Khurshid I, Anderson L, Downie GH, Pape GS. Sickle cell disease, extreme hyperbilirubinemia, and pericardial tamponade: case report and review of the literature. Crit Care Med 2002;30:2363-7.

8. Sheehy TW, Law DE, Wade BH. Exchange transfusion for sickle cell intrahepatic cholestasis. Arch Intern Med 1980; 140:1354-66.

9. Perini GF, Santos FPS, Ferraz Neto JBH, et al. Acute sickle hepatic crisis after liver transplantation in a patient with sickle beta-thalassemia. Transplantation 2010; 90:463-4.

10. Greenberg M, Daugherty TJ, Elihu A, et al. Acute liver failure at 26 weeks' gestation in a patient with sickle cell disease. Liver Transplantation 2009;15:1236-41.

11. Ross AS, Graeme-Cook F, Cosimi BA,
Chung R. Combined liver and kidney transplantation in a patient with sickle cell disease. Transplantation Feb 2002;73:6058.

12. Delis SG, Dervenis C. Is there a role of exchange transfusions in patients with sickle cell anemia and major liver surgery? European Society for Organ Transplantation 2007;20:299-300.

13. van den Hazel SJ, Metselaar HJ, Tilanus HW, et al. Successful liver transplantation in a patient with sickle-cell anaemia. Transpl Int 2003;16:434-6.

14. Lerut JP, Claeys N, Laterre PF, et al. Hepatic sickling: an unusual cause of liver allograft dysfunction. Transplantation 1999;67:65-8.

15. Emre S, Kitibayashi K, Schwartz ME, et al. Liver transplantation in a patient with acute liver failure due to sickle cell intrahepatic cholestasis. Transplantation 2000;69:675-7.

16. Lang T, Berquist WE, So SK, et al. Liver transplantation in a child with sickle cell anemia. Transplantation 1995;59:1490-2.

17. Mekeel KL, Langham MR, GonzalezPeralta R, et al. Liver transplantation in children with sickle-cell disease. Liver Transplantation 2007;13:505-8.

18. Vichinsky EP, Haberkern CM, Neumayr L, et al. A comparison of conservative and aggressive transfusion regimens in the perioperative management of sickle cell disease. N Engl J Med 1995;333:206-13.

19. Haberkern CM, Neumayr LD, Orringer EP, et al. Cholecystecomy in sickle cell anemia patients: perioperative outcome of 364 cases from the National Preoperative Transfusion Study. Blood 1997;89:1533-42. 